\title{
India-Kuwait: \\ Inter-Cultural Sensitivity, Cultural Intelligence and Conflict-handling Styles in Cross-cultural Interactions
}

\author{
Prachi BHATT
}

\begin{abstract}
The present explores inter-cultural sensitivity, cultural intelligence and conflicthandling style preferences of employees engaged in inter-cultural interactions. It further tests the influence of inter-cultural sensitivity, cultural intelligence on conflict-handling style preferences. Using self-report instruments, data was collected from respondents from India ( $\mathrm{N}=103)$ and Kuwait $(\mathrm{N}=71)$ involved in work-related interactions with each other. Findings reveal that Indian and Kuwait respondents significantly differ on the three dimensions studied. The results also reveal that influence of cultural intelligence and inter-cultural sensitivity dimensions on conflict-handling style preferences vary for Indian and Kuwait employees. The present work contributes to the largely limited work in the area and offers valuable information facilitating better understanding and application of effective conflict handling styles in India-Kuwait crosscultural work interactions.
\end{abstract}

Keywords: Conflict; inter-cultural sensitivity; cultural intelligence; conflict handling styles; India; Kuwait; cross-cultural interaction; effective conflict handling; cross-cultural conflict.

\section{Introduction}

With the deepened global exposure through various resources and channels, opportunities to interact with others across the borders have increased (Templer, Tay, \& Chandrasekar, 2006), and so has increased the scope of related conflicts. "Conflict style" is a culturally embedded, and culture plays a very important role in an individual's preference towards conflict styles (Ting-Toomey, 2006). A culturally diverse workplace is portrayed by differences in cultural values, attitudes, and work styles, which also have

\section{Prachi BHATT}

Associate Professor, OB \& HR, FORE School of Management, New Delhi

E-mail: prachi@fsm.ac.in dr.prachibhatt@gmail.com

Conflict Studies Quarterly

Issue 33, October 2020, pp. 20-41

DOI: $10.24193 / \mathrm{csq} .33 .2$

Published First Online: 05 October /2020 
been the concerns for organisations (Chan \& Goto, 2003; Sauceda, 2003). Thus, managerial focus has grown on the issues related to cultural diversity and conflicts induced due to cultural differences (Kaushal \& Kwantes, 2006), and on how to effectively manage them. Managing conflict is one of the new sets of global managerial skills considered important today. According to Miyahara, Kim, Shin and Yoon (1998), conflict and resolving conflict is a part of every culture, "the way it is expressed, perceived, and dealt with varies from culture to culture" (p. 506).

Understanding culture has evolved over region and time. In India, there lies a great opportunity for international and domestic companies to participate in the industry's growth and derive benefits out of it. According to the reports on India-Kuwait Trade and Economic Relation by Ministry of External Affairs, Government of India (2017; 2019), India-Kuwaiti relations have always had an important trade dimension involving a lot of cross-cultural interactions. This highlights the relevance to explore applicable cross-cultural aspects such as inter-cultural sensitivity (ICS), cultural intelligence (CQ), and conflict-handling styles of people belonging to globalized societies and working with each other.

Over the past few years, there has been an increased research focusing on the impact of cross-cultural aspects on conflict-handling (Gomez \& Taylor, 2017; Bercovitch \& Foulkes, 2012; Ting-Toomey, 2006). But previous studies on conflict management have majorly focused on investigation of western cultures' samples. But, studies that explore and compare conflict management styles between non-western cultures, such as Kuwait and India, are scant. Also, research assessing the association between conflict-handling styles, ICS and CQ dimensions are largely missing. Thus, the present study attempts to fill the gap by investigating the relationships between the above three important inter-cultural aspects and further attempts to test the influence of ICS, CQ on different conflict-handling style preferences of the Indian-Kuwait interactants.

The present study is beneficial on a number of levels. The results of this study can have important practical purposes in acknowledgement of the differences in ICS, CQ and conflict handling style preferences of India and Kuwait employees. Results can help to understand and to further facilitate future conflict management in the India-Kuwait intercultural work-settings.

\section{Theory and hypotheses development}

\subsection{Conflict and culture}

Conflict can occur in both cooperative and competitive contexts (Deutsch, 1973), which is concerned with low or high concern for self and low and high concern for others. Based on these two dimensions, five distinct behavioral conflict management strategies emerge i.e., integrating, obliging, dominating, avoiding, and compromising. 
Obliging (high concern for others and low concern for self); avoiding (low concern for both self and others); compromising (medium concern for self and others); problemsolving (high concern for self and others); and forcing/ competing (high concern for self vs. low concern for others). Later, significant contributors simplified this typology (Thomas-Kilmann, 1974; Holt \& DeVore, 2005).

According to Ting-Toomey, Yee-Jung, Shapiro, Garcia, Wright and Oetzel (2000), conflict interaction style "is learned within the primary socialization process of one's cultural or ethnic group. Individuals learn the norms and scripts of appropriate conflict conduct and effective conflict behavior in their ethnic and cultural environment" (p. 48). Researchers (Triandis, 2000; Vodosek, 2007) have proven that barriers and biases because of cultural difference, prejudices, and stereotypes increase the potential level of conflict in a culturally diverse setting more than in a culturally homogeneous workgroup. In cases of cross-cultural teams, cultural complexities emerge from different individualism or collectivism values (Staples \& Zhao, 2006). Cultural tensions, misperceptions can exaggerate the conflict at both cognitive and affective levels (De Wit, Greer, \& Jehn, 2012; Tenzer, Pudelko, \& Harzing, 2014). Difficulty in understanding different approaches and styles about other cultures influence work-teams immensely (Paletz, Miron-Spektor, \& Lin, 2014).

In the Indian context, researches have largely compared groups such as gen $Y$ and gen X (Mukundan, Dhanya, \& Saraswathyamma, 2013), Muslims and Hindus (Croucher, Holody, Hicks, Oommen, \& DeMaris, 2011), and gender (Jha, 2014) and found significant relationship between cross-cultural factors and conflict styles. Other researchers studied dynamics of negotiating behavior of Indians (Kumar, 2004), Indian software expatriates (Sulthana, 2016), and cross-cultural complexities in multicultural teams (Aza, 2017). Researches are scant covering conflict styles, ICS and CQ aspects especially in the Indian context, albeit these are important aspects for effectiveness in a culturally diverse work-settings.

\subsection{Inter-cultural sensitivity and conflict}

Inter-cultural sensitivity refers to "individual's ability to develop a positive emotion towards understanding and appreciating cultural differences that promotes appropriate and effective behavior in intercultural communication" (Chen \& Starosta, 1997, p. 5). ICS is associated with a person's emotions toward inter-cultural interactions (Triandis, 1977). The feeling of participation in an intercultural communication is "interaction engagement". The way to orient to or tolerate counterpart's culture and opinion is "respect for cultural differences" aspect of ICS. Interaction confidence is "concerned with how confident the parties interacting in the intercultural setting". Interaction enjoyment dimension deals with participant's positive or negative reaction towards communicating with people from different cultures. The effort put in by a party in an 
inter-cultural interaction to understand what is going on in an intercultural interaction is the "interaction attentiveness" dimension. ICS deals with the ability to learn and understand people belonging to different cultural backgrounds and hence being able to think and behave appropriately.

Indian organisations are faced with challenges of working in culturally different environments (Björkman \& Lervik, 2007; Ting-Toomey et al., 2000) as cultural complexities increase when interaction occurs cross-culturally. Gundara (2014) highlighted one possible way to manage and reduce conflicts encouraging the development of "interculturality". Cultural differences play a very important role in conflict-resolution between managers (Morris et al., 1998). According to Awang-Rozaimie, Amelia, Aiza, Siti-Huzaimah, and Adib (2013), the magnitude of ICS moderately facilitates cross-cultural adjustment. Although cultural sensitivity has gained importance at workplace, but very few researches have explored it in relation with conflict-handling styles (Clements, 2017; Yu \& Chen, 2008; Mao, 2010).

\subsection{Cultural intelligence and conflict}

Cultural intelligence (CQ) is "an individual's capability to function and manage effectively in culturally diverse settings... a specific form of intelligence focused on capabilities to grasp, reason, and behave effectively in situations characterized by cultural diversity" (Ang et al., 2007, p. 337). CQ deals with the ability of an individual to discern appropriate interactions and not merely cognizant awareness of emotions or social occurrences (Thomas \& Inkson, 2004). CQ is "meant to reflect the capability to deal effectively with people from different cultural backgrounds" (Thomas, 2006, p.78).

There are four components of CQ which include (a) cognitive, (b) meta-cognitive, (c) motivational, and (d) behavioral. Cognitive CQ "reflects knowledge of the norms, practices and conventions in different cultures acquired from education and personal experiences... those with high cognitive CQ understand similarities and differences across cultures" (Ang et al., 2007, p. 338). Whereas, meta-cognitive CQ "reflects mental processes that individuals use to acquire and understand cultural knowledge... those with high meta-cognitive CQ are consciously aware of others' cultural preferences before and during interactions... they also... adjust their mental models during and after interactions" (Ang et al., p. 338). Motivational CQ refers to the "capability to direct attention and energy toward learning about and functioning in situations characterized by cultural differences" (p. 338). It captures the ability to learn and act effectively in various situations. Finally, behavioral CQ is the "capability to exhibit appropriate verbal and non-verbal actions when interacting with people from different cultures... this includes having a wide and flexible repertoire of behaviors... exhibit situationally appropriate behaviors" (Ang et al., p. 338). Behavioral quotient refers to the flexibility of an individual to demonstrate appropriate actions with individuals from other cultural contexts (Ng, Van Dyne, Ang, \& Ryan, 2012; Ward, Wilson, \& Fischer, 2011). 
According to researches (Crowne, 2008; Engle \& Crowne, 2014; Moon, Choi, \& Jung, 2012), the international experience of individuals, however short, would impact CQ. CQ has evolved as a crucial dimension of success for individuals and organisations involved in consistent cross-cultural interactions (Ang, Van Dyne, \& Rockstuhl, 2015). Researchers highlight importance of CQ in conflict-handling (Ramalu, Rose, Kumar, and Uli, 2010). CQ has been found to enhance accuracy of decision making (Ang, et al., 2007), intercultural negotiation effectiveness (Van Dyne, Ang, Ng, Rockstuhl, Tan, \& Koh, 2012; Imai \& Gelfand, 2010), and interpersonal conflict resolution (Gonçalves, Reis, Sousa, Santos, Orgambídez-Ramos, \& Scott, 2016). Caputo, Ayoko, \& Amoo (2018), supports the moderating role of CQ between cultural orientations and conflict management style.

Scholars have argued that conflict is a culturally defined event. The management of inter-cultural interactions are emerging as a challenge in itself (Earley \& Ang, 2003; Dusi, Messetti, \& Steinbach, 2014). Hence, there has been a significant increase in the importance given to conflict-handling competencies of managers such as to understand, relate and behave in resolving conflicts across culturally diverse work environment. As Kuwait is one of the India's major trade partners, many deals and negotiations from time to time exist between them, but there is lack of evidence-based research that explores the dynamics between CQ ICS, and conflict-handling styles in the India-Kuwait context. Thus, it seemed relevant to explore the ICS, CQ and preferred conflict handling styles of the employees of these two countries who are engaged in cross-border interactions.

\section{The method}

One of the objectives is to explore and understand the difference in the ICS, CQ and conflict handling styles of the employees from India and Kuwait interacting with each other. The paper also explores the correlations of ICS and CQ dimensions with the preferred conflict handling styles of the respondents. It further explores the influence of both ICS and CQ dimensions on the preferred conflict handling styles of Indian and Kuwait respondents, respectively. So, for the employees engaged in India-Kuwait intercultural interactions with each other, the objectives and the hypotheses proposed are:

1. To explore and understand the difference in the ICS, CQ and preferred conflict handling styles of the respondents from India and Kuwait.

H1: There is a significant difference in ICS, CQ, and preferred conflict handling styles of the employees of India and Kuwait.

2. To explore the co-relationship (for India and Kuwait respondents) of preferred conflict handling styles with ICS and with CQ, respectively.

H2a: There is a significant co-relationship between preferred conflict-handling styles and ICS dimensions 
H2b: There is a significant co-relationship between preferred conflict-handling styles and CQ dimensions.

3. To explore the influence of ICS and CQ dimensions on the preferred conflict handling styles of Indian and Kuwait respondents.

H3: ICS dimensions and CQ dimensions influence the preferred conflict handling styles of Indian and Kuwait respondents.

\subsection{Participants}

Based on the objectives, the study sample entail respondents from India and Kuwait having the experience of cross-cultural interactions. Respondents were mainly engineers and managers working in major oil and gas companies belonging to both public sector and private sector companies of India and Kuwait.

\subsection{Data Collection}

Three widely cited tests were used to collect the data to ensure its robustness and accuracy in measuring the constructs used in the present study. To test participants' ICS, intercultural sensitivity scale was used (Chen \& Starosta, 2000a). This scale has demonstrated a good internal consistency. Cronbach's alpha reliability coefficients ranged between .79 and .89 (Chen \& Starosta, 2000b; Graf \& Harland, 2005; Petrović \& Zlatković, 2009). As mentioned in the above literature review, the scale entails five factors i.e., interaction engagement, respect for cultural differences, interaction confidence, interaction enjoyment, and interaction attentiveness. 24 items were randomly ordered to be rated on a five-point likert scale i.e., $(1=$ strongly disagree, and $5=$ strongly agree). Also, chronbach alpha calculated for this measure was 0.68 .

CQ scale (CQS), a 20-item scale developed by Ang et al. (2007) is one of the three most promising instruments for assessing cross-cultural competence (Matsumoto \& Hwang, 2013). CQS items were adopted for the present study (1=strongly disagree, and $5=$ strongly agree). In this research, cronbach's alpha for the total scale is .69 and for the subscales: .62 for meta-cognitive, .61 for cognitive, .68 for motivational, and .64 for behavioral quotient.

Dutch test for conflict handling was used to measure respondents' conflict handling style preferences. It captures two dimensions - concern for self and concern for others; five independent conflict management styles, as verified by De Dreu, Evers, Beersma, Kluwer and Nauta (2001) problem solving, yielding, forcing, avoiding, and compromising. It is a parsimonious and flexible instrument to assess conflict management styles at work (De Dreu et al., 2001). It is 20 -items Likert scale (1 being Not at all; and 5 being almost always) is widely used and has demonstrated consistent and excellent psychometric qualities coefficient values in previous studies. To the pre-existing 
instructions of the scale i.e., "Read each of the statements below and circle the response that you believe best reflects your position regarding each statement", was suffixed by i.e., "during my interactions with Indian counterparts" and "during my interactions with Kuwait counterparts" for Indian and Kuwait respondents, respectively. Chronbach alpha calculated for this measure was 0.72 . The questionnaire was administered both online and in hard-copy.

Table 1: Demographic details

\begin{tabular}{|c|c|c|}
\hline 1 & Gender & $\begin{array}{l}\text { India: } 24.2 \% \text { females and } 75.7 \% \text { males. } \\
\text { Kuwait: } 20.0 \% \text { females and } 80.0 \% \text { males }\end{array}$ \\
\hline 2 & Age & India: 36.5 yrs. and Kuwait: 33.7 yrs. \\
\hline 3 & Management level & $\begin{array}{l}\text { India: Jr.-Mid 20.3\%; Middle-Exec 37.8\%; Exe. } 41.7 \% \\
\text { Kuwait: Jr.-Mid 12.6\%; Middle-Exec 43.6.0\%; Exe. } 43.6 \%\end{array}$ \\
\hline
\end{tabular}

Table 1 reveals the demographic details regarding age, gender and management level of the respondents of the study. A total number of 174 filled questionnaires were used, i.e., 103 from India and 71 from Kuwait. The data was treated using SPSS 20.0.

\section{Result}

The following section deals with the findings obtained after employment of t-test and analyses. Firstly, the test of normality (Kolmogorov-Smirnov test as the sample size was more than 50) approved of using parametric tests for further analysis. Skewness and Kurtosis values are between -2 and +2 denoting the variables are approximately in a normal distribution.

Table 2: Mean, Inter-cultural sensitivity, and Cultural intelligence by country (one-way ANOVA)

\begin{tabular}{|c|c|c|c|c|c|c|c|c|c|c|}
\hline & & $\begin{array}{l}\text { Interaction } \\
\text { engagement }\end{array}$ & $\begin{array}{l}\text { Respect for } \\
\text { culture } \\
\text { Differences }\end{array}$ & $\begin{array}{l}\text { Interaction } \\
\text { Confidence }\end{array}$ & $\begin{array}{l}\text { Interaction } \\
\text { enjoyment }\end{array}$ & $\begin{array}{c}\text { Interaction } \\
\text { attentiveness }\end{array}$ & $\begin{array}{l}\text { CQ_Meta- } \\
\text { cognition }\end{array}$ & $\begin{array}{c}\mathrm{CQ}_{\text {n_tion }} \operatorname{cog} \\
\text { nit }\end{array}$ & $\begin{array}{l}\text { CQ_Moti } \\
\text { vaton }\end{array}$ & $\begin{array}{l}\text { CQ_Beh } \\
\text { ivor }\end{array}$ \\
\hline \multicolumn{2}{|c|}{ Country, t-test } & 15.44 & 21.60 & 11.84 & 22.30 & 5.71 & -6.05 & -3.41 & 10.48 & -1.10 \\
\hline \multicolumn{2}{|l|}{$\mathrm{p}$ value } & $0.00^{* *}$ & $0.00^{* *}$ & $0.00^{* *}$ & $0.00 * *$ & $0.00^{* *}$ & $0.00^{* *}$ & $0.00^{* *}$ & $0.00^{* *}$ & 0.27 \\
\hline India & Mean & 23.88 & 24.63 & 19.26 & 13.08 & 11.06 & 2.25 & 2.94 & 3.82 & 3.50 \\
\hline Kuwait & Mean & 19.32 & 18.07 & 15.23 & 8.59 & 9.94 & 3.01 & 3.45 & 2.59 & 4.04 \\
\hline \multicolumn{11}{|c|}{ Note: $*=p<0.05 ; * *=p<0.001$} \\
\hline
\end{tabular}

Results (Table 2) revealed that there is a significant difference in ICS and CQ between employees of India and Kuwait. However, only for CQ behavior, the difference between the two country's employees was not significant. 
Table 3: Mean scores, conflict handling styles by country and gender ( $\mathrm{t}$-test) and managerial levels (one-way ANOVA)

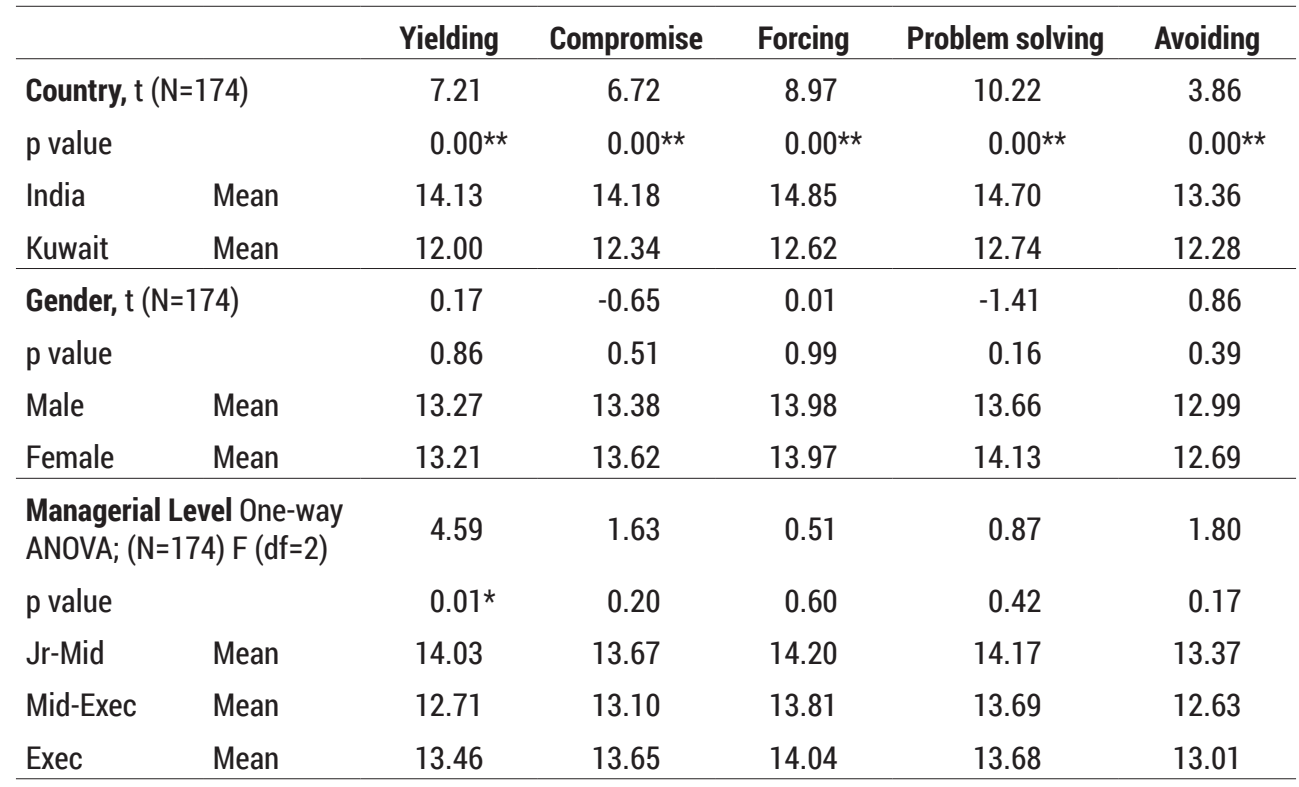

Note: ${ }^{*}=p<0.05 ; * *=p<0.001$

Table 3 presents the mean, t-test (country) analyses testing the difference in preferred conflict handling styles between Kuwait and Indian respondents. For all the five conflict handling styles, Indian respondents scored higher mean values than their Kuwait counterparts. It can be noticed that the highest score in case of India is for the forcing style and in case of Kuwait, it is problem-solving. Scores of Kuwait employees were lowest on the yielding style, and Indian employees scored lowest on the avoiding style of conflict handling style.

H1 was accepted revealing significant differences in the three dimensions i.e., ICS, CQ (except CQ behavior), and conflict-handling styles across India and Kuwait respondents.

For both the Indian and Kuwait respondents, $\mathrm{H} 2$ is accepted revealed in the significant correlations (as highlighted in Table 4) between conflict handling styles \& ICS; and between conflict-handling styles \& CQ.

To test hypothesis $\mathrm{H} 3$, multiple regression analyses (Table 5 and 6) depict the factors that predict the preferred conflict handling styles of the employees involved in IndiaKuwait interactions.

Multi-collinearity between variables CQ factors and ICS was checked. VIF values were found to be acceptable (less than 10) ranging between 1.02 and 2.20 across all the regression equations. 
Conflict Studies Quarterly

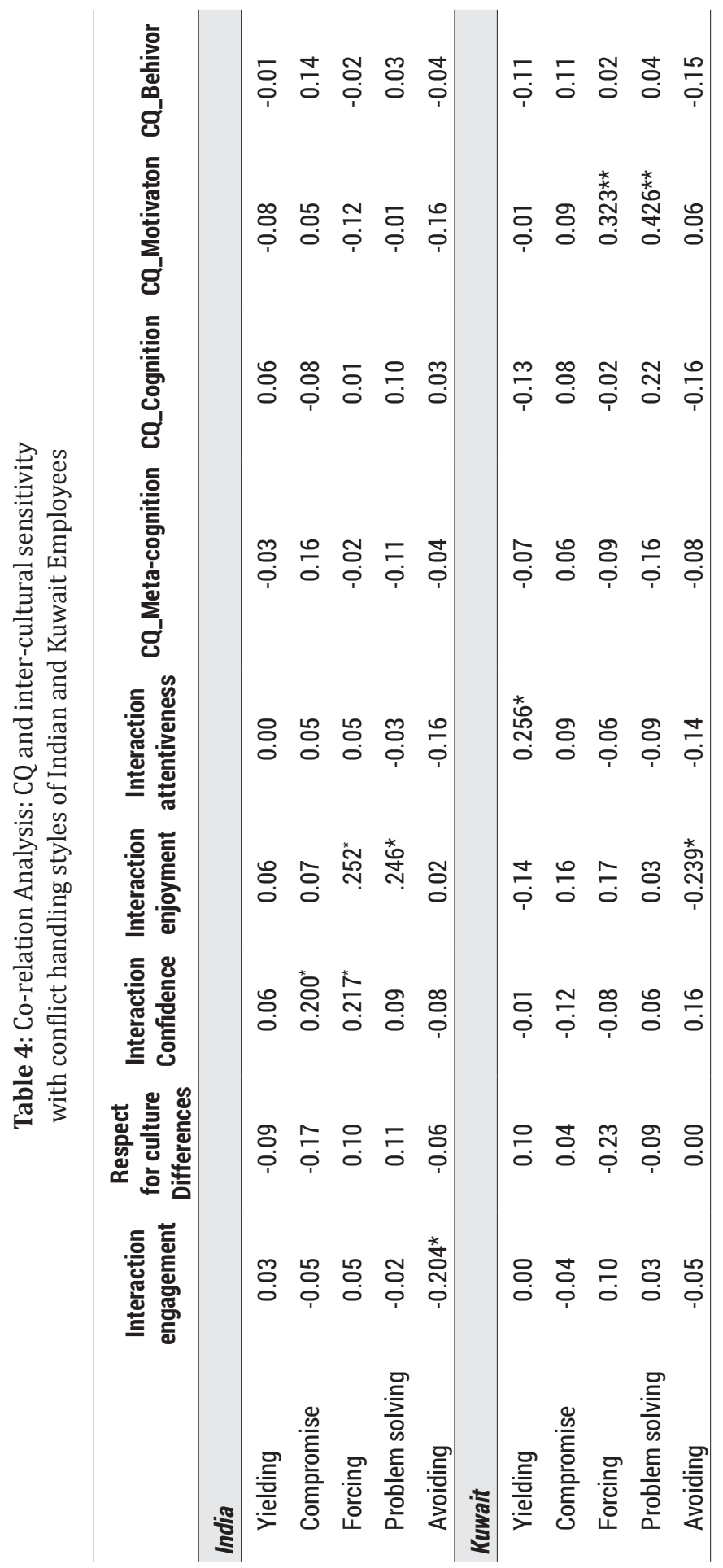


Table 5: Multiple Regression Analysis: Conflict handling styles of Indian employees in Indian-Kuwait intercultural interactions

\begin{tabular}{lccccc}
\hline India & Yielding & Compromise & Forcing & $\begin{array}{r}\text { Problem } \\
\text { Solving }\end{array}$ & Avoiding \\
\hline (Constant) & 14.74 & 10.90 & 8.10 & 10.20 & 18.00 \\
CQ meta-cognition & & & & & \\
CQ_cognition & & & & & \\
CQ_motivation & & & & & \\
CQ_behavior & & & & & -.20 \\
Interaction engagement & & & & & \\
Respect for culture Differences & -.16 & & & & \\
Interaction confidence & & .17 & .12 & & \\
Interaction enjoyment & & & .33 & .42 & \\
Interaction attentiveness & & & & & \\
F & 4.71 & $4.20^{*}$ & $4.90^{\star *}$ & $6.50 * *$ & $4.40 *$ \\
DF & 102 & 102 & 102 & 102 & 102 \\
R2 & .044 & .040 & .090 & .060 & .052 \\
R2adj & -.049 & .030 & .072 & .050 & .042 \\
\hline
\end{tabular}

Table 6: Multiple Regression Analysis: Conflict handling styles of Indian employees in Indian-Kuwait intercultural interactions

\begin{tabular}{lccccc}
\hline Kuwait & Yielding & Compromise & Forcing & $\begin{array}{r}\text { Problem } \\
\text { Solving }\end{array}$ & Avoiding \\
\hline (Constant) & 7.63 & 8.88 & 11.46 & 10.60 & 14.82 \\
CQ meta-cognition & & & & & \\
CQ_cognition & & & & & \\
CQ_motivation & & & .48 & .69 & \\
CQ_behavior & & & & \\
Interaction engagement & & & & & \\
Respect for culture Differences & & & & & \\
Interaction confidence & & & & & -.30 \\
Interaction enjoyment & & .19 & & & \\
Interaction attentiveness & .44 & & & & \\
F & $4.84^{\star}$ & .82 & $8.04^{\star *}$ & $15.30^{\star *}$ & $4.80^{* *}$ \\
DF & 70 & & 70 & 70 & 70 \\
R2 & .066 & .108 & .104 & .180 & .057 \\
R2adj & .052 & -.024 & .091 & .170 & .043 \\
\hline
\end{tabular}


Table 6 shows results highlighting the factors that predict the preferred conflict handling styles of the Kuwait respondents while interacting with the Indian counterparts.

\section{Discussion and Conclusion}

The present study finds its relevance in the given times of increasing requirements to deal with differences and manage conflicts. The mean scores of ICS score and CQ scores of Indian and Kuwait respondents reveal that the Indian respondents were more positive towards the inter-cultural communication and Kuwait employees were more focused towards understanding the process of the ongoing inter-cultural communication. The t-test and mean score analysis revealed that the Indian employees were higher than their Kuwait counterparts on the affective components of inter-cultural interactions. Further, in case of India, CQ motivation was higher than their Kuwait counterparts. This finding creates an opportunity to further explore sources of motivation of Indian respondents behind adapting to cross-cultural environment, such as external events- praise, appreciation during cross-cultural interactions. Kuwait respondents have scored higher than their Indian counterparts in CQ meta-cognition, and CQ cognition, indicating that Kuwait respondents focus more on gaining knowledge and overall awareness about the Indian culture, which according to Ang et al. (2007) helps them to plan and strategize. They also give attention to norms, practices, conventions, etc., to understand the differences that exist between the two cultures. This implies that Kuwait respondents' interactions were centered on cognitive aspects, as opposed to their Indian counterparts' interactions which centered on affective aspects of cross-cultural interactions. This could also be attributed to higher uncertainty avoidance orientation (Hofstede, 1984) of respondents of Kuwait than in the case of India. Also, in a collectivist society like Kuwait, where offence is believed to have led to loss of face reflects the decisions taken in an interaction or situation. A strong stance by a counter-part in work-related interactions can be implied to motivate Kuwait respondents to be more task focused. Future research can explore the reasons behind considerable focus on cognitive or affective aspects in cross-cultural interactions.

Significant difference is evident in the preference conflict handling styles of both Indian and Kuwait respondents. In case of India, the scores for avoiding were low, and Kuwait respondents gave less preference to yielding style. It is evident that when Indian and Kuwait employees interact with each other, Kuwait respondents prefer problem-solving and Indians preferred forcing styles more than other conflict handling styles.

Correlation analysis reveals the relationship between preferred conflict-handling styles and CQ and ICS of respondents involved in inter-cultural interactions between India and Kuwait. In case of the Indian respondents, results reveal the co-relationship between conflict handling styles with ICS dimensions and no such co-relationship between conflict-handling styles and CQ factors. Yielding styles did not correlate with 
either of the CQ or ICS dimensions. However, compromising style significantly and positively correlated with interaction confidence. Confidence while interacting of Indian respondents can be linked with their aim to explore potential of joint benefit for which both parties will give up something in order to reach an agreement (Yuan, 2010). Confidence while interacting with a counterpart of a different cultural background positively correlated with Indians' forcing style. Both forcing and problem-solving styles of conflict-handling emerged to be significantly and positively correlating with interaction enjoyment. Comparing the effect-size of emerged significant correlations with interaction enjoyment reveal that Indian counterparts' positive feeling and positive response toward the interaction is more likely to influence use of controlling styles in India-Kuwait inter-cultural settings. Correlations also reveal that negative feelings with respect to participating in an inter-cultural setting may cause Indian counterparts to use avoiding conflict style.

The results (Table 4) exhibit that in case of the Kuwait respondents, interaction attentiveness, i.e., putting efforts to understand during an interaction, significantly and positively increases the likelihood of using the yielding style. Results reveal that likelihood of Kuwait employees to avoid issues at hand when they be subjected to feeling not so positive about the ongoing interactions with Indian counterparts. Also, we may explain this finding as the likelihood of using this style to maintain a harmony situation (Huang, 2016). The Kuwait respondents with their high CQ motivation are more likely to use problem-solving, and forcing styles than using yielding, avoiding, and compromise styles of conflict handling.

Multiple-regression analysis helps to understand preference concerning conflict handling styles of employees engaged in India-Kuwait inter-cultural interactions. In this study, the low $\mathrm{R}^{2}$-square was observed in result of regression analyses. In general, an $\mathrm{R}^{2}$ of 0.75 is strong, 0.5 is moderate and 0.25 is weak (Wong, 2013). However, the low $\mathrm{R}^{2}$, indicating the large spread of data explained by independent variables, is often presented in social science, as human behaviour or satisfaction is difficult to predict (Frost, 2017). Also, Glenn and Shelton (1983) stated that eliminating the regression results with low $\mathrm{R}^{2}$ is not appropriate in social research, instead, it is recommended for better understanding and to compare to other research. Moksony (1990) demonstrated that $\mathrm{R}^{2}$ is not useful to compare either contribution of independent variable or goodness of the model fit and suggested to use the unstandardized regression coefficient for the explanatory power and the standard error for the goodness of fit.

In case of Indian respondents, no significant predictors emerge to explain their preference of using yielding style. But, in case of Kuwait respondents, interaction attentiveness predicts the use of yielding style of conflict handling. Interaction attentiveness is related to the effort to understand the ongoing process of intercultural communication. Yielding style deals with meeting the other person's needs. It also means sacrificing 
one's own needs. It can be understood that as Kuwait employees try to increase their efforts for understanding the ongoing process and counterparts' needs, causing them to willingly sacrifice their own needs to meet the counterparty's needs. Inter-culturally sensitive individuals may resort to a yielding style when they do not need to give up too much of their personal needs, but to maintain a harmonious relationship by yielding something for other parties' satisfaction. Also, researchers have supported that $90 \%$ of managers are using collaborating and accommodating as a mode of conflict resolving, which is found to be more commonly used in handling conflict in middle-east including managers in Kuwait (Yousry, El-Halwany, \& Shiha, 2014; Ali, Taqi, \& Krishnan, 1997). Kuwait being a high-context communication environment (Berger, Silbiger, Herstein, \& Barnes, 2015), conflict handling styles tend to be avoiding and obliging (Croucher et al., 2012), which are contrary to the integrative and sometimes even main conflict style (Ryan and Daly, 2018). Also, another possible explanation could be high levels of cultural knowledge could lead to cognitive overload (Camerer, Loewenstein, \& Weber, 1989; Hall, Ariss, \& Todorov, 2007). However, further research may explore willingness to engage in sacrifice, or perhaps one's tendency towards altruism or possibly the role of information overload.

Interaction confidence tests how confident participants feel while managing the uncertainties in cross-cultural interaction contexts. Indian respondents' confidence predicts their preference towards using compromise style to handle the conflict situation. This particular style is also associated with their aim to reach a mutually acceptable decision that usually works for both parties. Also, the result can be explained with the help of Instone, Major and Bunker (1983)'s work, according to which individuals who have high self-confidence are more likely to use influence attempts and less coercive strategies than those subjects who have low self-confidence. Willingness of a person to understand the differences, and still hold a positive view of the process are the ones who will be willing to "give up something with the hope of getting something in exchange from the other party when needed" (Rahim, 1985, p. 84). These people change their own opinion either because they found sufficient reasons to do so or simply to avoid continued confrontation (Lussier, 2010; Reich, Wagner-Westbrook, \& Kressel, 2007). In case of Kuwait respondents, no significant factor emerged to be influencing their preference of compromise style.

The confidence to manage cross-cultural interactions and enjoyment during such interactions has influence on the Indians respondents' forcing style of handling conflict while interacting with their Kuwait counterparts. However, interaction enjoyment i.e., positive effect, contributed more than interaction confidence to explain Indians' preference for forcing style. The results imply that enjoying the process of ongoing interaction improves the understanding which would further support use of problem-solving style of conflict. Result support previous researches (Lyubomirsky, King, \& Diener, 2005; 
Greeff \& de Bruyne, 2000) according to which individuals in positive moods or feelings are more likely to solve conflicts through collaboration. It can be inferred that interaction enjoyment would drive employees to work towards the best interest of both the parties in inter-cultural interactions.

In case of the Kuwait respondents, CQ Motivation predicts their preference for using forcing and problem-solving styles of conflict handling. Motivational CQ captures the ability to learn and act effectively in various situations. Here, Kuwait respondents' willingness to acknowledge and appreciate cultural differences, and positive reaction encourages them to not compromise with their interests but to take necessary actions to achieve them. At the same time motivation dimension of CQ encourages Kuwait respondents to consider other party's viewpoints and prefer problem solving approach in business interactions with Indian counterparts.

In case of the Indian respondents, results reveal that interactions which support participation or discussion to resolve problems, reduces their likelihood of using avoiding style while interacting with Kuwait counterparts than when they realise less participation in the interaction. It can be inferred that such interactions which fail to encourage Indian respondents' participation also fail to satisfy their own goals as well as that of others, accordingly affecting their preference for conflict aversive style i.e., avoiding. Also, research support that avoiding style is preferred non-confrontational style in collectivist cultures (Croucher, et al., 2012; Ali, Taqi, \& Krishnan, 1997).

However, in case of Kuwait respondents, interaction enjoyment plays a key role while interacting with their Indian counterparts. Based on the result, interaction enjoyment negatively predicts avoiding style of Kuwait respondents. This reveals that Kuwait employees' negative reaction during the interactions leads to their preference to use avoiding style. Also, interaction enjoyment's significant negative relationship with avoiding style have found support in research (Tong \& Chen 2008). According to Al-Sabah, (2015), when Kuwaitis have bad experiences or know there would be a difficulty in handling the demands of the other party, they resort to a method of "avoiding". Also, they usually use this style to maintain a harmony situation (Huang, 1999). The results regarding avoiding styles support that individuals from predominantly high-context cultures (which are often collectivistic as well) are more likely to avoid or oblige in conflicts (Ohbuchi, Fukushima and Tedeschi, 1999; Ting-Toomey et al., 1991).

\section{Implications}

Involvement of different communication styles, expectations, beliefs and conflict handling interactions across diverse cultures is inevitable. However, the influence of cultural diversification in managerial transactions has not been sufficiently recognized in the resaerch literature. 
In India, experiences of overseas and expatriate assignments are prevalent, and demand of globally oriented managers with intercultural competence has increased (Srinivasan, 2017). Choice of a particular conflict-handling style would influence the conflict resolution process. relationships and tasks between the conflicting parties. It is crucial for employees working in global teams in India and Kuwait to have knowledge/skill to identify and resolve conflicts effectively. Thus, the results highlight cross-cultural aspects relevant for effectively managing conflict between employees belonging to two different cultures i.e., India and Kuwait, and draws implications.

Result supports that ICS (Chen \& Starosta, 1997) and CQ (Triandis, 2006) have an influence on preferred conflict-handling styles of the Indian and Kuwait respondents, respectively. It highlights behavioural implications of parties in conflict. For e.g., the result reveal that both parties must encourage positive affect during the cross-cultural interactions which would promote participation from their counterparties. This would also encourage preference for problem solving style by Indian respondents and discourage use of avoiding style by Kuwait interactants. Indian respondents must learn to appreciate Kuwait respondents' concerted efforts in learning about Indian functioning, culture etc., which has been found to be influencing preference for problem solving style of Kuwait counterparts. The results also stress on the importance of acquiring CQ and ICS towards adapting to new and unfamiliar culturally diverse work environments. The study provides implications regarding skill-set required for selection of officials for global assignments. International and global business assignments demand a set of competencies in their leaders and managers belonging to different cultural backgrounds to interact and manage conflicts effectively. Another area of implications is sensitizing job incumbents dealing in cross-cultural scenarios through effective cross-cultural training programs. According to research, significant elements that need to be incorporated in inter-cultural trainings are CQ (Earley \& Peterson, 2004; Janssens \& Brett, 2006) and ICS (Jain, 2013; Chen \& Starosta, 1997). CQ and ICS will enhance or support team collaboration and effective team decisions in overseas assignments. Managing conflict situations can become stressful and difficult, thus ignorance about diverse culture can be disastrous for employees involved in cross-cultural interactions or overseas assignments. Hence, intercultural training programs on improving ICS and CQ is important for companies seeking to enhance effectiveness of multicultural work interactions. In the context of globalisation, the results find its implications extending from India-Kuwait workforce to the global workforce dealing in multicultural work settings.

Present study also has limitations and poses future research possibilities. Participants working in the oil and gas sector could limit the generalizability of the results. Future research could explore the findings of the present reaserch with more representative samples. Studying conflict in a variety of cultural contexts would help in refining the understanding of conflict management in cross-cultural interactions. Assessment of 
conflict style preference and ICS with the help of other data collection techniques such as observation, peer-rating could also improve the quality of responses. Hence, call for further research overcoming this limitation to confirm the results.

Other aspects of culture could also throw more light on the results presented in this study, for example, religion. Religion has been identified as one of the predictors of conflict handling in Indian context (Croucher, et al, 2011), hence studies could explore if these results remain true with the religion as predictor variables in case of India and Kuwait.

CQ motivation and interaction enjoyment emerge as two major aspects affecting forcing and problem-solving conflict styles of both Kuwait and Indian respondents, respectively. CQ motivation acts as one of the main drivers for individuals to learn and to be able to function in new and culturally diverse settings. Also, sense of enjoyment and positive feelings about the interactions are crucial. According to Chen (2006), positive attitude along with communication skills would reduce cultural difficulties and ensure effectiveness of international assignments. However, research exploring social interactions entailing give and take of positive cues while communicating with others, to better adjust, and adequately collect information in an intercultural interaction is needed. Further research regarding lingua-cultural differences could be insightful. Alnashi's (2012) work revealed that managers from different cultures tend to have different conflict management styles and that "face" plays a big role on the conflict styles used. Thus, study of verbal or non-verbal exchanges related to CQ motivation and interaction enjoyment can be instrumental in improving positive reaction in cross-cultural interactions between India and Kuwait. This can throw more light on the way participants infer meaning from an uncertain nature of intercultural interaction and perhaps able to sustain the relationship along with attaining the task.

Technological advancements in business, new virtual platforms of interactions are considerably used which influence team and individual performances (Walsh, Gregory, Lake, \& Gunawardena, 2003; Yoo \& Alavi, 2004). Hence, it seems a very relevant and practical question to be studied to explore the instrumental role of technology in managing conflicts in inter-cultural interactions.

Overall, the present research adds value to largely limited knowledge of the differences in conflict resolution style preferences across two globalised cultures and working environments i.e., of India and Kuwait. The result present interplay between ICS, CQ, and conflict-handling styles of employees and help realizing the extent to which it contributes to a more effective conflict management styles. The results find its application for people management and skill development of people involved in inter-cultural interactions. Along with opening avenues for future research, the results offer some valuable information to facilitate our understanding and applications for better conflict management in such cross-cultural work interactions. 


\section{Acknowledgements}

I gratefully acknowledge the infrastructural support provided by the FORE School of Management, New Delhi towards the preparation of this paper. This is part of the reaserch work carried out as part of the Center for Psychometric Testing and Research, FORE School of Management, New Delhi.

\section{References}

1. Ali, A. J., Taqi, A. A., \& Krishnan, K. (1997). Individualism, Collectivism, and Decision Styles of Managers in Kuwait. The Journal of Social Psychology, 137(5), 629-637.

2. Alnashi, S. (2012). An Intercultural competence study of conflict management style amongst managers in cross-cultural American organizations-Qual Comm and Genentech. Master of Communication Thesis, Report No. 2012:062, University of Gothenburg, Department of Applied Information Technology Gothenburg, Sweden.

3. Al-Sabah, F. (2015). An empirical investigation of middle-east conflict management styles. Doctoral dissertation. College of Business, Arts and Social Sciences, Brunel Business School, Brunel University.

4. Ang, S., \& Van Dyne, L. (2008). Handbook of cultural intelligence: Theory, measurement, and applications. Armonk: M. E. Sharpe.

5. Ang, S., Van Dyne, L., \& Rockstuhl, T. (2015). Cultural intelligence: Origins, conceptualization, evolution, and methodological diversity. In M. J. Gelfand, C.-Y. Chiu, \& Y.-Y. Hong (Eds.), Advances in culture and psychology: Vol. 5. Handbook of advances in culture and psychology, Vol. 5 (pp. 273-323). Oxford: Oxford University Press.

6. Ang, S., Van Dyne, L., Koh, C. K. S., Ng, K. Y., Templer, K. J., Tay, C., \& Chandrasekar, N. A. (2007). The measurement of cultural intelligence: Effects on cultural judgment and decision making, cultural adaptation, and task performance. Management and Organization Review, 3(3), 335-371.

7. Awang-Rozaimie, A. S., Amelia, A. T., Aiza, J., Siti-Huzaimah, S., \& Adib, S. (2013). Intercultural sensitivity and cross-cultural adjustment among Malaysian students abroad. Journal of Educational and Social Research, 3(7), 693-703.

8. Aza. H.T. (2017). A Case Study of Cross-Cultural Complexities and Interpersonal Conflict Faced by Project Managers in Multicultural Software Development Project Teams. Doctoral dissertation. College of Arts, Humanities and Social Sciences-Department of Conflict Resolution Studies, Nova Southeastern University. .

Bercovitch, J., \& Foulkes, J. (2012). Cross-cultural effects in conflict management: Examining the nature and relationship between culture and international media tion. International Journal of Cross-Cultural Management, 12(1), 25-47. DOI: 10.1177/ 1470595811413105.

9. Berger, R., Silbiger, A., Herstein, R., \& Barnes, B. R. (2015). Analyzing business-to-business relationships in an Arab context. Journal of World Business, 50(3), 454-464.

10. Björkman, I., \& Lervik, J. E. (2007). Transferring HRM practices within multinational corporations. Human Resource Management Journal, 17(4), 320-335. DOI: http:// dx.doi.org/10.1111/j.1748-8583.2007.00048.x. 
11. Camerer, C., Loewenstein, G., \& Weber, M. (1989). The curse of knowledge in economic settings: an experimental analysis. Journal of Political Economy, 97, 1232-1254.

12. Caputo, A., Ayoko, O. B., \& Amoo, N. A. (2018). The moderating role of cultural intelligence in the relationship between cultural orientations and conflict management styles. Journal of Business Research, 89, 10-20.

13. Chan, D. K., \& Goto, S. G. (2003). Conflict resolutions in the culturally diverse workplace: Some data from Hong Kong employees. Applied Psychology: An International Review, 52(3), 441-460.

14. Chen, G. M., \& Starosta, W. J. (1997). A review of the concept of intercultural sensitivity. Human Communication, 1, 1-16.

15. Chen, G. M. (2006). Asian Communication Studies: What and Where to Now. Review of Communication, 6(4), 295-311.

16. Chen, G. M., \& Starosta, W. J. (2000a). Intercultural Sensitivity. In L. A. Samovar, \& R. E. Porter, (Eds.), Intercultural Communication: A Reader (pp. 406-414). Belmont: Wadsworth Publishing Company.

17. Chen, G. M., \& Starosta, W. J. (2000b). The Development and Validation of the Intercultural Sensitivity Scale. Human Communication, 3, 1-15.

18. Clements, A. (2017). Generation Me: Millennial Intercultural Sensitivity and Conflict Management Styles in the Group Setting. Retrieved from https://scholarsbank.uor egon.edu/xmlui/handle/1794/22291.

19. Croucher, S. M., Bruno, A., McGrath, P., Adams, C., McGahan, C., Suits, A., \& Huckins, A. (2012). Conflict styles and high-low context cultures: A cross-cultural extension. Communication Research Reports, 29(1), 64-73.

20. Croucher, S. M., Holody, K. J., Hicks, M. V., Oommen, D., \& DeMaris, A. (2011). An examination of conflict style preferences in India. International Journal of Conflict Management, 22, 10-34.

21. Crowne, K. A. (2008). What Leads to Cultural Intelligence?. Business Horizons, 51(5), 391-399.

22. De Dreu, C. K. W., Evers, A., Beersma, B., Kluwer, E. S., \& Nauta, A. (2001). A theory-based measure of conflict management strategies in the workplace. Journal of Organizational Behavior, 22(6), 645-668.

23. de Wit, F. R C, Greer, L. L., \& Jehn, K. A. (2012). The paradox of intragroup conflict: A meta-analysis. The Journal of Applied Psychology, 97(2), 360-390.

24. Deutsch, M. (1973). The resolution of conflict: Constructive and destructive processes. New Haven: Yale University Press.

25. Dusi, P., Messetti, G., \& Steinbach, M. (2014). Skills, attitudes, relational abilities \& reflexivity: competences for a multicultural society. Procedia - Social and Behavioral Sciences, 112(1), 538-547. DOI: 10.1016/j.sbspro.2014.01.1200.

26. Earley, P., \& Ang, S. (2003). Cultural Intelligence: Individual Interactions across Cultures. Palo Alto: Stanford University Press. 
27. Earley, P. C., Peterson, R. S., (2004). The Elusive Cultural Chameleon: Cultural Intelligence as a New Approach to Intercultural Training for the Global Manager. Academy of Management Learning and Education, 3(1), 100-115.

28. Engle, R. L., \& Crowne, K. A. (2014). The Impact of International Experience on Cultural Intelligence: An Application Of Contact Theory In A Structured Short-Term Programme. Human Resource Development International, 17(1), 30-46.

29. Frost, J. (2017). How to interpret R-squared in regression analysis?. Statistics By Jim. Retrieved from https://statisticsbyjim.com/regression/interpret-r-squared-regression/.

30. Glenn, N. D., \& Shelton, B. A. (1983). Pre-adult background variables and divorce: A note of caution about overreliance on explained variance. Journal of Marriage and the Family, 45(2), 405-410.

31. Gomez, C., \& Taylor, K. A. (2017). Cultural differences in conflict resolution strategies: A US-Mexico comparison. International Journal of Cross-Cultural Management, 18(1), 33-51.

32. Gonçalves, G., Reis, M., Sousa, C., Santos, J., Orgambídez-Ramos, A., \& Scott, P. (2016). Cultural intelligence and conflict management styles. International Journal of Organizational Analysis, 24(4), 725-742.

33. Graf, A., \& Harland, L. K. (2005). Expatriate Selection: Evaluating the Discriminant, Convergent and Predictive Validity of Five Measures of Interpersonal and Intercultural Competence. Journal of Leadership and Organizational Studies, 11, 46-62.

34. Greeff, A. P., \& de Bruyne, T. (2000). Conflict management style and marital satisfaction. Journal of Sex \& Marital Therapy, 26(4), 321-334.

35. Gundara, J. H. (2014). Global and civilizational knowledge: Interculturality, citizenship, and student exchange programs. Intercultura, 72(1), 3-13.

36. Hall, C. C., Ariss, L., \& Todorov, A. (2007). The illusion of knowledge: When more information reduces accuracy and increases confidence. Organizational Behavior and Human Decision Processes, 103, 277-290.

37. Hofstede, G. (1984). Culture's consequences: International differences in work-related values. Beverly Hills: Sage Publications.

38. Holt, J. L., \& DeVore, C. J. (2005). Culture, gender, organizational role, and styles of conflict resolution: A meta-analysis. International Journal of Intercultural Relations, 29(1), 165-196.

39. Huang, L. L. (2016). Interpersonal harmony and conflict for Chinese people: A yin-yang perspective. Frontiers in psychology, 7, 847.

40. Imai, L., \& Gelfand, M. J. (2010). The culturally intelligent negotiator: The impact of cultural intelligence (CQ) on negotiation sequences and outcomes. Organizational Behavior and Human Decision Processes, 112, 83-98.

41. Instone, D., Major, B., \& Bunker, B. B. (1983). Gender, self-confidence, and social influence strategies: An organizational simulation. Journal of Personality and Social Psychology, 44, 322-333.

42. Jain, S. (2013). Experiential training for enhancing intercultural sensitivity. Journal of cultural diversity, 20(1), 15-20. 
43. Janssens, M., \& Brett, J. (2006). Cultural intelligence in global team: a fusion model of collaboration. Group Organization Management, 31(1), 124-153.

44. Jha, S. (2014). Gender Perspective on Conflict Resolution Styles of Aspiring Indian Managers. Asia Pacific Journal of Management Research \& Innovation, 6(4), 126-133.

45. Kaushal, R., \& Kwantes, C. T. (2006). The role of culture and personality in choice of conflict management strategy. International Journal of Intercultural Relations, 30(5), 579-603.

46. Kumar, R. (2004). Brahmanical Idealism, Anarchical Individualism, and the Dynamics of Indian Negotiating Behavior. International Journal of Cross-Cultural Management, 4(1), 39-58.

47. Lussier, R. N. (2010). Human relations in organizations: Applications and skill building. Singapore: Mc Graw Hill/Irwin.

48. Lyubomirsky, S., King, L., \& Diener, E. (2005). The benefits of frequent positive affect: Does happiness lead to success?. Psychological bulletin, 131( 6), 803-855.

49. Mao, Y. (2010). Does culture matter? Relating intercultural communication sensitivity to conflict management styles, technology use, and organizational communication satisfaction in multinationals in China. Doctoral dissertation defended at the Scripps College of Communication, Ohio University).

50. Matsumoto, D., \& Hwang, H. C. (2013). Assessing Cross-Cultural Competence: A Review of Available Tests. Journal of Cross-Cultural Psychology, 44, 849-873. D0I: $10.1177 / 0022022113492891$.

51. Ministry of External Affairs. (2017). India-Kuwait Relations. New Delhi: Ministry of External Affairs.

52. Ministry of External Affairs (2019). India-Kuwait Bilateral Relations. New Delhi: Ministry of External Affairs.

53. Miyahara, A., Kim, M., Shin, H., \& Yoon, K. (1998). Conflict resolution styles among collectivist cultures: A comparison between Japanese and Koreans. International Journal of Intercultural Relations, 22(4), 505-525.

54. Moon, H. K., Choi, B. K., \& Jung, J. S. (2012). Previous international experience, cross cultural training, and expatriates' cross-cultural adjustment: Effects of cultural intelligence and goal orientation. Human Resource Development Quarterly, 23(3), 285-330.

55. Moksony, F. (1990). Small is beautiful. The use and interpretation of R2 in social research. Szociológiai Szemle (special issue), 130-138.

56. Morris, M. W., Williams, K. Y., Leung, K., Larrick, R., Mendoza, M. T., Bhatnagar, D., Li, J., Kondo, M., Luo, J. L., Hu, J. C. (1998). Conflict Management Style: Accounting for Cross-National Differences. Journal of International Business Studies, 29, 729-747. DOI:10.1057/palgrave.jibs.8490050.

57. Mukundan, S., Dhanya, M., \& Saraswathyamma, K. P. (2013). A study on the conflict resolution styles of Generation Y students in Indian context. International Journal of Global Business, 6(1), 81-90.

58. Ng, K., Van Dyne, L., Ang, S., \& Ryan, A. (2012). Cultural intelligence: a review, reflections and outcomes. International Journal of Conflict Management, 18(4), 345-375. 
59. Ohbuchi, K. I., Fukushima, O., \& Tedeschi, J. T. (1999). Cultural values in conflict management: Goal orientation, goal attainment, and tactical decision. Journal of cross-cultural psychology, 30(1), 51-71.

60. Paletz, S. B. F., Miron-Spektor, E., \& Lin, C-C. (2014). A cultural lens on interpersonal conflict and creativity in multicultural environments. Psychology of Aesthetics, Creativity, and the Arts, 8, 237-252.

61. Petrović, D., \& Zlatković, B. (2009). Intercultural Sensitivity of Future Primary School Teachers. In N. Popov, C. Wolhuter, B. Leutwyler, M. Mihova, J. Ogunleye and Z. Bekiroğulları (Eds.), Comparative Education, Teacher Training, Education Policy, and Social Inclusion (pp. 121-128). Sofia: Bureau for Educational Services.

62. Rahim, M. A. (1985), A strategy for managing conflict in complex organizations, Human Relations, 38(1), 81-89.

63. Ramalu, S. S., Rose, R. C., Kumar, N., \& Uli, J. (2010). Doing business in global arena: An examination of the relationship between cultural intelligence and cross-cultural adjustment. Asian Academy of Management Journal, 15(1), 79-97.

64. Reich, W. A., Wagner, B. J., \& Kressel, K. (2007). Actual and ideal conflict styles and job distress in a health care organization. The Journal of Psychology, 141(1), 5-15.

65. Ryan, J. C., \& Daly, T. M. (2019). Barriers to innovation and knowledge generation: The challenges of conducting business and social research in an emerging country context. Journal of Innovation \& Knowledge, 4(1), 47-54.

66. Sauceda, J. M. (2003). Managing intercultural conflict effectively. In L. A. Samovar and R. E. Porter (Eds.), Intercultural communication: A reader (pp. 385-405). Belmont: Wadsworth.

67. Srinivasan, J. (2017, June 19). Intercultural awareness, a must for the success of MNCs in India. The Economic Times. Retrieved from https://economictimes.indiatimes.com/ magazines/panache/between-the-lines/intercultural-awareness-a-must-for-thesuccess-of-mncs-in-india/articleshow/59218790.cms?from=mdr (accessed June 10, 2019).

68. Staples, D. S., \& Zhao L. (2006). The effects of cultural diversity in VTs versus face-toface teams. Group Decision and Negotiation, 15, 389-406.

69. Sulthana, H. R. (2016). An exploratory investigation on cross cultural impact study on Indian software expatriates. International Journal of Applied Research, 2(2), 535-540.

70. Templer, K., Tay, C., \& Chandrasekar, N. A. (2006). Motivational cultural intelligence, realistic job preview, realistic living conditions preview, and cross-cultural adjustment. Group \& Organization Management, 31(1), 154-173.

71. Tenzer, H., Pudelko, M., \& Harzing, A-W. (2014). The impact of language barriers on trust formation in multinational teams. Journal of International Business Studies, 45(5), 508-535.

72. Thomas, D. C., \& Inkson, K. (2004). Cultural Intelligence: People Skills for Global Business. San Francisco: Berrett-Koehler.

73. Thomas, K., \& Kilmann, R. (1974). Thomas-Kilmann Conflict Mode Instrument. Tuxedo: XICOM. 
74. Thomas, D. C. (2006). Domain and development of cultural intelligence the importance of mindfulness. Group and Organization Management, 31(1), 78-99.

75. Ting-Toomey, S., Gao, G., Trubisky, P., Yang, Z., Kim, H. S., Lin, S. L., \& Nishida, T. (1991). Culture, face maintenance, and styles of handling interpersonal conflict: A study in five cultures. International Journal of Conflict Management, 2, 275-296.

76. Ting-Toomey, S. (2006). Managing intercultural conflict effectively. In L. A. Samovar, R. E. Porter and E. R. McDaniel (Eds.), Intercultural communication: A reader (pp. 366377). Belmont: Wadsworth.

77. Ting-Toomey, S., Yee-Jung, K. K., Shapiro, R. B., Garcia, W., Wright, R. J., \& Oetzel, J. G. (2000). Ethnic/cultural identity salience and conflict styles in four US ethnic groups. International Journal of Intercultural Relations, 24(1), 47-82.

78. Triandis, H. (1977). Interpersonal behaviour. Monterey: Brooks/Cole.

79. Triandis, H. C. (2006). Culture and conflict. In L. A. Samovar, R. E. Porter and E. R. McDaniel(Eds.),Interculturalcommunication:Areader(pp.22-31). Belmont:Wadsworth.

80. Triandis, H. C. (2000). Culture and conflict. The International Journal of Psychology, 35(2), 145-152.

81. Van Dyne, L., Ang, S., Ng, K., Rockstuhl, T., Tan, M., \& Koh, C. (2012). Sub-dimensions of the four-factor model of cultural intelligence: expanding the conceptualization and measurement of cultural intelligence. Social and Personality Psychology Compass, 6(4), 295-313. DOI: 10.1111/j.1751-9004.2012.00429x.

82. Vodosek, M. (2007). Intragroup conflict as a mediator between cultural diversity and work group outcomes. International Journal of Conflict Management, 18(4), 345-375.

83. Walsh, S. L., Gregory, E. M., Lake, M. Y., \& Gunawardena, C. N. (2003). Self-construal, facework, and conflict styles among cultures in online learning environments. Educational Technology Research and Development, 51(4), 113-122.

84. Ward, C., Wilson, J., \& Fischer, R. (2011). Assesing the predictive validity of cultural intelligence over time. Personality and Individual Differences, 51(2), 138-212.

85. Wong, K. K. (2013). Partial least squares structural equation modeling (PLS-SEM) techniques using Smart PLS. Marketing Bulletin, 24(1), 1-32.

86. Yoo, Y., \& Alavi, M. (2004). Emergent leadership in virtual teams: what do emergent leaders do?. Information and Organisation, 14(1), 27-58.

87. Yu, T., \& Chen, G. M. (2008). Intercultural sensitivity and conflict management styles in cross-cultural organizational situation. Intercultural Communication Studies, 17(2), 149-161.

Yousry, M. M., El-Halwany, A. E., \& Shiha, E.M. (2014). Conflict Management and Preferred Style for Resolving Conflict. SUST Journal of Engineering and Computer Science, 15(2), 63-71.

88. Yuan, W. (2010). Conflict management among American and Chinese employees in multinational organizations in China. Cross Cultural Management: An International Journal, 17(3), 299-311. 